Frontiers: The Interdisciplinary Journal of Study Abroad Volume III, Fall 1997

\title{
Health and Disease
}

\author{
David E. Hornung \\ Catherine H. Shrady
}

Introduction

E VEN A S U PER F I C I A L comprehension of medicine in any culture requires an understanding of the way health and disease are related to the broader cultural context in which they exist. Viewed from the other direction, an understanding of medical traditions not only reveals certain social values but also affords a glimpse into the structure of the culture (Kakar, 192). In other words, healing may be a lens through which to examine culture. In support of this view, Foucault (1964) suggests each culture has its own view of insanity which highlights the public obsessions of the time. Certainly the diagnosis and management of madness is not independent of social history, for each age defines insanity at a different point and in a different fashion (Kakar, 1982).

A close examination of a healing tradition's assumptions about reality (metaphysics), ways of acquiring knowledge (epistemology), and systems of beliefs and values (ideology) are a powerful focus for a more general attempt to study culture (Beinfield and Koragold, 1991). The intention of this paper is not to offer a comprehensive view of any particular healing tradition. In the few pages that follow, it would be impossible to adequately describe even a single healing tradition. Rather, generalizations concerning the metaphysics, epistemology, and ideology of Western and non-Western healing traditions are used to suggest how healing traditions might be related to broader cultural contexts. Healing traditions outside of allopathic medicine are here referred to by the term "non-Western." This is not meant to suggest a "them vs. us" mentality. If anything it suggests a nonspiritual vs. spiritual dichotomy. Questions raised when different healing traditions encounter each other and sometimes conflict are powerful teaching tools. The hope is that 
these questions and generalizations might provide the beginning framework by which a student studying abroad could approach culture through issues of health and disease.

\section{MEDICINE IN THE WEST}

\section{Metaphysics and Ideology}

In the West, the underlying premise of science is that the universe, like a machine, can be dissected into constituent parts. Reality is found in the visible configuration of substance: that which can be measured. Events occur according to unfluctuating principles (Beinfield and Korngold, 1991). Descartes, a French mathematician, conceived of the world as a gadget, stating "I do not recognize any difference between machines made by craftsmen and various bodies that nature alone composes" (Rodis-Lewis, 1978). Following this logic, Descartes argued the human body must also be a gadget. If this is true, it then follows that science and therefore medicine should be the description of how things work.

Scientific studies seem to support the mechanistic view of the body as being composed of distinct and separate parts, connected yet autonomous. Anatomists have observed at both the macroscopic and microscopic level, differences in the structure of the various organs of the body, whereas physiologists have described different functions for different parts of the body.

\section{Epistemology and Application}

\section{Home Remedies}

In Western cultures, changes in physiological functions such as an increase in body temperature or an unexpected pain, which are often thought to be related to disease states, do not prompt all people to seek the same treatment. Responses to almost any set of symptoms range from waiting for a considerable period of time hoping they will disappear to immediately seeking professional medical advice. Within this continuum of responses, many people will initially begin to treat themselves (Imperato, 1977). 
Common components of the home remedy therapeutic regimens include a modification in activity patterns, a change in diet, and the use of over-the-counter medications. Although the efficacy of a few of these remedies has been supported scientifically, most have either not been tested or have not been shown to be effective. Despite the lack of scientific validation, these home remedies continue to be utilized because of the generation-to-generation transfer of observations about their effectiveness (Imperato, 1977). Chicken soup is given for a number of illnesses ranging from the flu to pneumonia. Strong alcoholic drinks are prescribed for cold symptoms and ginger ale is given for epigastric distress. Within the West, the variety of home remedies is extensive and varies considerably from family to family.

The generation-to-generation lore about the effectiveness of these remedies occurs because they are usually prescribed in the management of self-limited illnesses; the patient will recover whether or not they are used. However, even without scientific validation, a strong case can be made for their usefulness as a nonspecific measure in the psychological sense. Some home remedies are even given credit by practicing physicians (Imperato, 1977).

\section{Healing Professionals}

When symptoms do not respond to home remedies, most ill individuals in the West seek help by consulting an allopathic physician. Of course, these individuals expect positive results, and studies have suggested the act of making an appointment can, itself, make some people feel better. An increasing number of people also expect to be told why they got sick. They want the infecting agent to be identified and its method of entering the body to be described. For the office visit there are also expectations. Patients expect a waiting room (usually with a relatively long wait), a nurse and/or receptionist, and diplomas and other kinds of citations on the wall. Patients expect the atmosphere to be somewhat antiseptic (Imperato, 1977).

The contact with the physician is expected to begin with a history and physical. The history includes a determination of the nature of 
the complaint, how long it has been present, and if it has happened before. Questions about social habits (smoking, drinking, and amount of physical exercise) and occupational activities are also anticipated. The physical exam begins with the area specific to the complaint. When no specific area is identified, the exam begins with the head (eyes, ears, nose, and throat) and then proceeds to the rest of the body. Patients will usually not consult a physician whose practices differ widely from these expected protocols (Imperato, 1977).

There are two possible results from the history and physical examination. First, a diagnosis, usually based on statistical inferences, may be made on the basis of the history and physical. Because it is usually true, a physician may assume, for example, that certain flu-like symptoms are due to a bacterial infection. As a result, antibiotic therapy may be initiated before the presence of a bacteria has been documented. Second, the physician may suspect a serious problem, may be uncertain of the diagnosis, or may simply wish to delay treatment and so additional procedures are ordered. Eventually a differential diagnosis is made in which possible diagnoses are ranked according to the likelihood that they represent what is actually wrong with the patient.

Although the practices of a particular physician may vary greatly from what is considered standard medical care, this is often not noticed by the patients, because the physician is dealing with illnesses that are self-limiting. In other words, as was true for the home remedies, physicians often are managing self-limited illnesses; the patient will recover regardless (and in a few cases despite) the prescribed treatment. Thus it is not uncommon to hear patients describing in glowing terms a physician who is not highly thought of by knowledgeable colleagues (Imperato, 1977). This is especially true of physicians who seemed to be genuinely concerned with the welfare of their patients. Medical students are taught how to make a patient feel the physician is concerned about him or her. For example, it is common practice to keep personal notes in the patient's medical records, so when the patient returns for a visit, the physician can ask about a particular pet or hobby. 
Frontiers: The Interdisciplinary Journal of Study Abroad Volume III, Fall 1997

Perspective

Western medicine has traditionally been viewed as being international, with clear norms consistently applied wherever it is practiced. This view, however, is challenged by the following case study: "An American opera singer in Vienna consulted an Austrian doctor, who prescribed suppositories for her headache. Not used to receiving headache medication in this form, she ate one" (Payer, 1988, p. 23).

A number of studies also challenge the idea of an international consistency. For example, when physicians from a number of countries evaluated the same set of death certificates, their determination of the cause of death varied depending on the home country of the physician. As another example, the diagnosis of psychiatric patients varies significantly from country to country as well. As Payer (1990) reports, "until a few years ago a patient labeled schizophrenic in the United States would likely have been called manic-depressive or neurotic in England and delusional psychotic in France." Therapies can vary as widely as the diagnosis. Homeopathic remedies, which are usually dismissed in the United States, are widely prescribed in many parts of Europe.

Medicine in each Western country has a characteristic of its own. For example, German physicians seem to be preoccupied with the cardiovascular system. When examining the same electrocardiogram (ECG), a German physician is more likely than an American to find something wrong (Payer, 1990). On the other hand, English physicians tend to focus on the external causes of disease, and are much more likely to prescribe antibiotics than their counterparts in other parts of Europe. The English list of the twenty most frequently prescribed medications include three classes of antibiotics, whereas in Germany the list includes none (Payer, 1990).

Medicine in the United States can be described in one word: Aggressive. Benjamin Rush (a signer of the Declaration of Independence) felt that one of the great obstacles to the development of medicine was the "undue reliance upon the powers of nature in curing disease." (Davies et al., 1983) Unfortunately this 
view has not changed much in the past two hundred years. There is more of almost every type of surgery done per capita in the United States than in anywhere else in the world (Payer, 1990).

In the West, medical treatment is not entirely a science. While scientifically-conducted studies can, perhaps, quantify the risks and benefits for a treatment, these assessments are statistical. That is, a given treatment will work only a certain percent of the time, and side effects will be seen in another percent of patients receiving that treatment. The weighing of the risks and benefits for a particular patient is the art of medicine, and will always be made, at least in part, on a cultural scale. There is no pat answer, no equation that can determine with certainty the best treatment for a particular patient at particular point in his or her life (Payer, 1988).

Implications

Beinfield and Korngold (1991) and many others have argued that "When people are like machines, doctors become like mechanics. The mechanic occasionally performs routine maintenance but mostly intervenes to execute emergency repairs." Body parts, like machine parts are then standardized and breakdowns become predictable. Standardized diseases derive from standard causes, and treatment regiments are fixed. People in the West normally think of themselves as separate, isolated individuals. So it is not surprising that when they are ill, they tend to separate themselves from the illness, thinking of it as an alien presence, a thing in itself. The illness is not a part of self, it is something to be removed from an otherwise healthy being (Beinfield and Korngold, 1991).

Some also feel Western medicine was not set Up to advise people on how to stay well. Physicians only fix what is broken. Disease (in the form of tumors, infections, stones) can be removed with drugs and surgery. The physician can wage war against disease (evil) but has no real mechanism to promote health (good). As a consequence of focusing attention on the disease, "curing" the disease becomes of paramount importance. At its extreme, this philosophy can result in the treatment being a success but the patient dying (Greenwood and Nunn, 1992). 
Frontiers: The Interdisciplinary Journal of Study Abroad Volume III, Fall 1997

Some interventions also produce tragic long-term effects on health. Iatrogenesis, or treatment-induced illness, can result from drugs, radiation, and chemotherapy. Approximately one out of every five people treated acquires an iatrogenic illness (Beinfield and Korngold, 1991; Greenwood and Nunn, 1992).

As science was able to describe the abnormal functioning of the body more accurately, people lost faith in the ability of the body to heal itself; and as doctors became experts they acquired power over their patients. Medicine became a technically complicated and exclusive priesthood with a language all its own. As a result, people felt the power to cure themselves came from outside themselves. For the patient, belief was detached from the body's self-healing abilities and transferred to the "experts"-the physicians.

In addition, no conceptual framework exists in the West which allows a therapeutic approach based on feeling alone. Conventional medicine tries to look after the body only and leaves psychiatry to look after problems of the mind. When Western physicians cannot find anything wrong physiologically, they have no choice but to deny their patient's experience of illness, invalidating the patient rather than medicine itself (Beinfield and Korngold, 1991). In the West there is a belief in rationalism, causality, objectivity. The assumptions work well when in an acute emergency situation, but are perhaps of more limited value when an illness becomes chronic (Greenwood and Nunn, 1992).

\section{MEDICINE OUTSIDE THE WEST}

\section{Metaphysics and Ideology}

Agrarian cultures experience power through nature and aspire to be in harmony with the seasons, rhythms, and patterns that connect all things with each other. For example, the ancient Chinese perceived human beings as a microcosm of the universe surrounding them, subject to the same forces that motivate the macrocosm. They imagine themselves as part of one unbroken wholeness called Tao, a singular relational continuum without and within. This thinking predates by five thousand years the dissection 
of humans from nature that Western culture performed in the seventeenth century (Beinfield and Korngold, 1991).

In the Islamic tradition, nature is the handiwork of God and it works according to laws that have been inlaid in it by God. Whenever God creates something, it falls into a pattern with the rest, resulting in cosmos rather than in chaos. A universally acclaimed statement in Islamic tradition is "God has sent down a treatment for every ailment" or "There is a medicine for every ailment such that if the right medicine hits a corresponding ailment, health is restored by God's permission." Health and disease (unhealth) are universal conditions wherever life in any form is found, and further, to avoid or cure disease is as much a natural law as the law of gravity (Nasr, 1976; Rahman, 1989).

A distinctly identifiable Hindu medical tradition, the Ayurvedic, stretches back two millennia in India. The theory is intertwined with the theological and liturgical discourses of the time. Medical texts articulate religious issues and religious texts include issues of diagnosis and therapies. Hindu medicine, like many non-Western medical traditions, never became separated from the rest of life's pursuits (Desai, 1989).

As the above examples suggest, many non-Western medical approaches can be characteri2ed as being spiritual. Spiritual medicine can be used to mean two different things, although both are allied and sometimes confused. One refers to the belief in a spiritual or ethical or psychological cure for diseases that may be physical or spiritual. Thus, a physical illness may be cured, for example, by recitation of prayers or by reestablishing a balance within the body. The other belief is that illness, particularly mental illness or madness, is caused by supernatural forces (Rahman, 1989).

Epistemology and Application

\section{Home Remedies}

The perception of illness in non-Western countries is about the same as what is seen in the West. In general, individuals react to changes in normal physiology by concluding they are ill. A variety of 
Frontiers: The Interdisciplinary Journal of Study Abroad Volume III, Fall 1997

home remedies are tried consisting of measures which closely parallel those employed in the West. These home remedies often include herbal preparations from local flora. In a general sense, these preparations correspond to the over-thecounter medications available in the west (Beinfield and Korngold, 1991; Imperato, 1977).

\section{Healing Professionals}

When an illness does not respond to home remedies, it is viewed as being serious and, at least sometimes, considered to have a supernatural cause. Thus there is a dualist (both physical and spiritual) system of disease causation, a departure from the Western physical-only cannon of pathophysiology.

The next step is for the patient to go to a traditional practitioner who deals with the cause of the disease. Often patients who visit such practitioners are told why they became ill. In Western societies, the physician describes how the patient got sick. "You have the flu which you contracted by breathing in the virus." In many nonWestern cultures the patient may be told "you are sick because your ancestor spirits are angry that you have ignored sacrificing to them," or "you are sick because you lack the proper balance of forces within your body" (Imperato, 1977).

There are noticeable similarities throughout the world about how the competency of the practitioner is evaluated. There are expectations about how the practitioner should look and act, and there are expected physical elements as well.

The therapy prescribed by the healing professional may necessitate several visits, or it may be implemented at the time of the first visit and then repeated at home. It is expected the patient will share in these ritual acts. As in the West, most disease states are self-limiting and so they will resolve on their own. As is the case in the West, cures are often attributed to the practitioner. When the rituals fail, failures are rarely attributed to the practitioner. Either the patient did not follow the prescription carefully enough, the supernatural cause is more powerful than originally thought, or the disease was the way things were meant to be.

Many non-Western approaches also embrace the idea that the best remedy for calamity is to avert it; the best cure for sickness is 
prevention. A medical Chinese classic written in the second century B.C. states: "Maintaining order rather than connecting disorder is the ultimate principle of wisdom. To cure disease after it appears is like digging a well when one already feels thirsty, or forging weapons after the war has already begun" (Beinfield and Korngold, 1991).

Within a spiritual reality the world is like a garden. The garden is nature-the living earth and the human person. When people are like gardens, then physicians are like gardeners. Their task is to promote vitality. The gardener does not make the garden flourish. Nature does. The gardener peruses and nurtures the interaction between the garden and the environment (Beinfield and Korngold, 1991; Kaptchuk, 1983).

Unlike in the West where the sick person is often isolated from others, in many non-Western countries the sick person is the focus of attention and receives recovery wishes from relatives, friends, and neighbors. In many cultures where the climate permits, the patient will lie on a mat in front of his/her residence and so is extremely accessible to well wishers. Visitors often offer their own therapeutic advice. As a result, in many cultures the number of people involved in the care of a sick individual far exceeds the number seen with patients in the West (Imperato, 1977).

In the Western model, physicians are entrusted with the active (powerful) role whereas patients are assigned the passive (powerless) one. In opposition, the medical technology of most nonWestern cultures is basic, economical, and highly transportable. Medicine in these locations envisions a condition without suffering and shows a way to get there. The way is not to search for a panacea, a "silver bullet," but to engage in the ongoing process of learning to become more viable, more contiguous: more in tune with the cosmos and the spirits (Beinfield and Korngold, 1991; Kaptchuk, 1983).

In many non-Western countries, science and tradition have never achieved separate and equal status. Attitudes toward the body, mind, and environment emphasize confluence rather than differentiation; the body has not quite become separate from the subject and the Western mastery over nature has never quite become a value (Desai, 19239). 
Frontiers: The Interdisciplinary Journal of Study Abroad Volume III, Fall 1997

Lessons from Healing Traditions

Human freedom in the traditional non-Western context seems to imply an increase in the potential to experience different inner states while limiting action in the outer world to stereotypes and unquestioning adaptation. The non-Western emphasis has been on the pursuit of an inner differentiation while keeping the outer world constant. In contrast, the notion of freedom in the West is related to an increase in the potential for acting in the outer world and enlarging the sphere of choices, while keeping the inner state constant to that of a rational, waking consciousness from which other modes of inner experience have been excluded as deviations. Each group has constantly underestimated the strength and attraction of the other's freedom ideal. Healers and their healing traditions need to be understood on their own terms and their own grounds (Kakar, 1982).

Healing Traditions in Conflict

The final section of this paper deals with healing traditions in conflict. Certainly the distinctions of Western and non-Western medicine are becoming blurred. A student from a non-Western country studying in the United States would be surprised by the "non-Western" treatment options available. Ayurvedic physicians are found in most metropolitan areas and acupuncturists are practicing throughout the United States. Homeopathic remedies are widely discussed and herbal treatments are commonplace. Likewise, an American student studying in a non-Western country would be surprised at the availability of Western medicine.

There are numerous examples of what happens when Western and non-Western medicine collide. The Nestle infant formula case in Africa is a prime example. African mothers, thinking Western medicine offered their babies the best chance for survival, used infant formula instead of breast milk to feed their young. Because 
these mothers did not understand all the subtleties of using infant formula, many babies died needlessly.

An illustration of the way in which healing, and in particular healing traditions in conflict, can be used as a lens through which to examine culture is the following case study.

A group of Western tourists are traveling in a non-Western country. As they are driving around the countryside they see a large tree in the distance and decide that would be a pleasant place to have lunch. As they get closer, they discover a boy about ten years old sitting under the tree. The tourists do not speak the same language the boy does, but with the help of their driver, who has a limited facility with the language of the boy, they discover the boy, who is a member of a local nomadic tribe, has been left under the tree to die. The healers from the boy's tribe have not been successful in treating this child, and as is the custom of the tribe, after a number of separation rituals, the boy was left where he has been found. The boy does not seem distressed about the situation, and he seems prepared to accept his death. What should the tourists do?

Should the tourists choose to examine the child, they will find he exhibits classic symptoms of appendicitis, a condition that, if untreated, will most likely prove fatal. With the vehicle provided by the tourists, a Western-style hospital is within a few hours' drive. The expectation is that an appendectomy would save the boy's life, but there are significant language problems should the tourists wish to attempt to communicate further with the boy.

This case study raises a host of questions that can be used to illuminate cultural beliefs-to illustrate that healing traditions can provide the lens through which to examine culture. An example is cultural attitudes toward death and dying. The child does not appear to be distressed by his situation and apparently has accepted that he has been left to die. What might this reveal about his culture's view of death? What does the tourists' dilemma suggest about the attitude toward death in the West? Were the tourists to take the boy to the hospital and thereby "save" him, would he be "saved" in the eyes of his tribe? Were the child ever to find his nomadic tribe again (not a trivial problem) would the members of his tribe accept him back after the separation ritual, or would they consider him to be a 
Frontiers: The Interdisciplinary Journal of Study Abroad Volume III, Fall 1997

ghost, in effect dead? Would the child be saved and alive in his own eyes? Might his life after surgery be, from his point of view, worse than death? Who will take care of him after the surgery? How will he survive? Perhaps the boy does not consider death to be the end. Many Westerners claim a similar belief, yet why do they still attempt to avoid death at all costs? Whose discomfort are the tourists really concerned with: the boy's or their own?

The case also raises a number of questions concerning cultural attitudes toward children. Because of the language barrier and the child's lack of contact (until now) with Western culture, would the boy be capable of understanding he can be cured using a healing tradition that involves cutting away part of his body? Would it be possible (or necessary) to obtain informed consent? What does the belief in informed consent reveal? Would the tourists' decision be easier if this sick child were in Europe or the United States? What if the person left to die was an adult?

Myriad other issues are raised by this case study. Are the tourists and the boy operating under the same understanding and definitions of health and disease? Do outsiders have the right to interfere) In the United States, interference in a case like this not only would be considered appropriate, in some states it would be a legal requirement. However, does that right of interference extend to another culture? What is of greater value-life for its own sake or the respecting of culture practices even if the latter results in death? Are there absolute values or truths that transcend culture, or is everything subject to cultural relativism?

Grappling with a case such as this can be an effective technique for using healing traditions in conflict; to raise questions concerning metaphysics, epistemology, and ideology; and to challenge cultural beliefs, biases, and assumptions. To repeat what was stated at the beginning of this paper, questions raised when different healing traditions encounter each other are powerful teaching tools. The hope is that these questions and generalizations might provide the beginning framework by which a student studying abroad could approach culture through issues of health and disease. 
References

Beinfield, Harriet, and Korngold, Efrem (1991). Between Heaven and Earth: A Guide to Chinese Medicine. Ballantine Books, New York.

Davies, N.E., Davies, G.H., and Sanders, E.D. (1983). "William Cobbert, Benjamin Rush and the Death of George Washington." Journal of the American Medical Association 249: 912-915.

Desai, Prakash N. (1989). Health and Medicine in the Hindu Tradition. Continuity and Cohesion. Crossroad Publishing Company, New York.

Greenwood, Michael, and Nunn, Peter (1992). Paradox and Healing. Paradox Publishers, Victoria, Canada.

Foucault, Michel (1965). Madness and Civilization: A History of Insanity in the Age of Reason. Pantheon Books, New York.

Imperato, Pascal James (1977). Africa Folk Medicine: Practices and Beliefs of the Bambara and Other Peoples. York Press, Baltimore.

Kakar, Sudhir (1982). Shamans, Mystics and Doctors: A Psychological Inquiry into India and Its Healing Traditions. The University of Chicago Press, Chicago.

Kaptchuk, Ted (1983). The Web that Has No Weaver. Congdon and Weed, New York.

Nasr, Seyyed Hoossein (1976). Islamic Science: An Illustrated Study. Westerham Press Ltd., Westerham, England.

Payer, Lynn (1988). Medicine and Culture: Varieties of Treatment in the United States, England, West Germany, and France. Henry Holt and Company, New York.

Payer, Lynn (1990). "Borderline Cases How Medical Practice Reflects National Culture.” The Sciences. July/August: 38-42.

Rodis-Lewis, Genevieve (1978). "Limitations of the Mechanical Model in the Cartesian Conception of an Organism," In Descartes, Michael Hooker, ed. Johns Hopkins University Press, Baltimore.

Rahman, Fazlur (1989). Health and Medicine in the Islamic Tradition: Change and Identity. Crossroad Publishing Company, New York. 